\title{
UV-Matrix-assisted laser desorption/ionization time-of-flight mass spectrometry analysis of synthetic polymers by using nor-Harmane as matrix
}

\author{
Rosa Erra-Balsells $*^{a}$ and Hirosi Nonami ${ }^{b}$ \\ ${ }^{a}$ CIHIDECAR-CONICET, Departamento de Química Orgánica, Facultad de Ciencias Exactas \\ y Naturales, UBA, Pabellón II, 3P Ciudad Universitaria, 1428 Buenos Aires, Argentina, and \\ ${ }^{b}$ Plant Biophysics/Biochemistry Research Laboratory, College of Agriculture, Ehime \\ University, 3-5-7 Tarumi, Matsuyama 790-8566, Japan \\ E-mail: erra@qo.fcen.uba.ar
}

Dedicated to Professors Edmundo A. Ruveda and Roberto A. Rossi

(received 19 Aug 03; accepted 11 Nov 03; published on the web 30 Nov 03)

\begin{abstract}
The matrix-assisted ultraviolet laser desorption/ionization time-of-flight mass spectra (UVMALDI-TOF-MS) analysis of some synthetic polymers was studied. The results obtained by using nor-harmane, gentisic acid (GA) and other UV-MALDI matrices, in positive and negative ion modes, were compared.

Nor-harmane worked as an efficient matrix for the synthetic polymers belonging to the families of polyethylenglycol (PEG), polymethylmethacrylate (PMMA), polystyrene (PS) and poly(dimethyl)siloxane (PDMS). This behaviour was quite noticeable in negative ion mode for polar-protic polymers (PEG) and in both ion modes for non-polar polymers (PS). For the latter analysis the addition of $\mathrm{Ag}^{+}$salts was not necessary for the ionization process. The formation of Ag clusters when $\mathrm{Ag}^{+}$salts are used as the cationizing agent is discussed. Because the initiation of the UV-MALDI process is a photochemical reaction (matrix $+\mathrm{hv}(337 \mathrm{~nm}) \rightarrow$ matrix*), the acid-base character of nor-harmane in the ground and the lower electronic excited singlet state, together with other photophysical properties are briefly discussed.

The excellent results obtained in the analysis of commercial synthetic polymers with norharmane allow us to propose these analyte-matrix systems for UV-MALDI-TOF-MS calibration.
\end{abstract}

Keywords: nor-Harmane, synthetic polymers, PEG, PMMA, PS, PDMS, Ag salts, Ag clusters, UV-MALDI matrix, UV-MALDI-TOF-MS

\section{Introduction}


Matrix-assisted ultraviolet laser desorption/ionization time-of-flight mass spectrometry (UVMALDI-TOF MS) $)^{1-3}$ has become a versatile and important tool for the determination of molecular masses of macromolecules such as synthetic polymers ${ }^{4-6}$ and bio-polymers. ${ }^{7-9}$ The principal of UV-MALDI involves ionizing macromolecules for TOF-MS analysis by diluting them in a suitable matrix of small organic molecules which absorb UV-laser photons. Currently, two parameters appear critical for effective MALDI-MS; the wavelength of the irradiating laser source and the chemical and physical properties of the matrix in which the analyte of interest is embedded. Karas and Hillenkamp ${ }^{2}$ first reported nicotinic acid as a matrix to desorb large proteins with a UV-laser (266 nm). Since then most of the compounds reported as useful matrices have been substituted aromatic compounds containing hydrogen donor groups, such as sinapinic acid $^{3}$ and gentisic acid, ${ }^{10}$ although some neutral and basic matrices also have been reported. 2,3,4,7,8, 10,11 Pyridoindole compounds such as commercial $\beta$-carbolines (9H-pyrido[3,4$b$ ]indoles) have been reported as useful matrices for proteins, ${ }^{12-15}$ sulfated carbohydrates ${ }^{12,13,15-18}$ and some non-commercial synthetic polymers (polyesters, polyamides and silesquioxanes). ${ }^{19-25}$ Mercaptobenzothiazoles have also been reported as useful matrices for synthetic polymers. ${ }^{5}$

It is interesting to point out that, although the dependence on wavelength of the laser source has been taken into account, ${ }^{26-29}$ little attention has been paid to the chemical structure (functional groups or geometry) and photochemical properties of potential matrix compounds. ${ }^{30}$ Although it has been claimed that the performance of potential MALDI matrices depends largely on their chemical properties, this aspect is still under discussion, ${ }^{30,31}$ and not many studies have been made from this point of view. ${ }^{32}$ In connection with this aspect, we have recently described the potential use of a large family of new synthetic pyrido indole polycyclic compounds, as UVMALDI matrices for proteins, synthetic polymers and oligosaccharides. ${ }^{33}$ We suggested that the simultaneous presence of an acidic indole $\mathrm{NH}$ group and a basic pyridine $\mathrm{N}$ group in an aromatic polycyclic structure might be the cause of their matrix behavior.

In continuing this study, we herein report the results obtained for UV-MALDI-TOF MS analysis of synthetic commercially available polymers (Figures 1-6) by using nor-harmane as matrix. Nor-harmane is a commercial $\beta$-carboline (9H-pyrido[3,4-b]indole) which contains both the indole NH group and the pyridine N group in its structure (Figures 9 and 10, Table 1).

Synthetic polymer MS capabilities and challenges have expanded dramatically. In an early report in 1988 Tanaka described for the first time the laser desorption of intact polymer molecular ions for masses up to 22,000 Da (polypropylenglycol and polyehytlenglycol) using fine metallic particles as the laser-absorbing matrix. ${ }^{1}$ After these experiments, Danis in 1992 reported the analysis of poly(acrylic acid) and poly(styrene sulfonic acid) using organic compounds as matrices and standard MALDI sample-preparation methods. ${ }^{34}$ The interest in analyzing synthetic polymers by UV-MALDI-TOF MS has steadily increased during recent years based on the discovery of several matrices for synthetic polymer analysis. Thus, carboxylic acids (trans-3-indolacrylic acid (IAA), 2,5-dihydroxybenzoic acid or gentisic acid (GA), sinapinic acid (SA), 2-(4-hydroxyphenylazo)-benzoic acid (HABA), and 5-chlorosalicylic acid), phenols (dithranol), neutral compounds (2-nitrophenyl octyl ether, 1,4-di(2-5-phenyl- 
oxazolyl)benzene, and all-trans-retinal) and soft basic compounds (carbostyril 124) together with some metals have been employed. ${ }^{1,5,6,35,36}$

Even today, the successful characterization of synthetic polymers by UV-MALDI-MS is strongly dependent firstly on the chemical structure of the polymer and secondly on experimental and instrumental factors. It is important to point our that not all synthetic polymers are easily analyzed and polymers with different chemical structures may require different sample handling for a successful analysis. From a practical standpoint, analyzable polymers can be classified into four groups: I, water-soluble polymers (solvent, water; poly(acrylic acid) (PAA) and polyethylenglycol (PEG)); II, polar organic-soluble polymers (solvent, ehanol, methanol, acetonitrile; polymethylmethacrylate (PMMA)); III, nonpolar organic-soluble polymers (solvent, THF, DMFA, trifluoroacetic acid (TFA), $\mathrm{HCCl}_{3}$; polystyrene (PS), polyvinyl chloride PVC, polyethylene PE) and IV, low-solubility polymers (solvent, DMSO; cured polyimide (PI) polyester (PES) and polyamide (PA). Sample preparation for the first three classes of polymers is faily well established. ${ }^{5,6,34,35}$ Nonsoluble polymers includes polymers soluble in solvents that are not compatible with known matrix materials. Thus, these are the most difficult to analyze by UV-MALDI because a homogeneous mixture of matrix and analyte that promotes polymermatrix interaction is not easy prepared, or just because the solvent required is not recommended in MALDI technique (i.e., DMSO). Low-soluble and nonsoluble polymers are generally not analyzable by UV-MALDI although the successful use of DMSO in the analysis of chiral polyhydroxy polyamides and the details for the sample preparation method has been described. ${ }^{20}$

Nor-harmane has been shown to be a good UV-MALDI matrix for the analysis of a wide variety of non-commercial synthetic polymers ${ }^{19-25}$ and bio-macromolecules, ${ }^{6,9,12,13,16,17}$ In the present study commercially available synthetic polymers such as PEG, PMMA, PS and poly(dimethyl)siloxane (PDMS) have been selected for UV-MALDI analysis with nor-harmane. These experiments have been conducted in positive and negative ion modes and the efficiency of the desorption/ionization processes, with and without ionizing salt, have been compared. As Ag salt as cationizing was not neccessary in PS analysis, the advantage of this fact is discussed in detail in the present paper.

The results obtained by using nor-harmane are compared with those obtained with gentisic acid (GA) and other UV-MALDI matrices, in positive and negative ion modes.

Ultraviolet laser desorption (LD) TOF-MS $\left(\lambda_{\text {exc }}=337 \mathrm{~nm}\right)$ of nor-harmane is also described (Table 1). Because of the initiation of UV-LD and UV-MALDI are photochemical processes ( nor-harmane $+\mathrm{h} v(337 \mathrm{~nm}) \rightarrow$ nor-harmane*), the electronic spectra (UV-absorption and emission spectra) of nor-harmane together with its $\mathrm{pK}_{\mathrm{a}}$ values in the ground and the electronic excited singlet states (Figure 9) are provided. Furthermore, the measured oxidation potential $\left(E_{\text {ox }}\right)$, the optimized geometry, the electrostatic potential 3D isosurface (Figure 10) and the calculated relative proton affinity (PA) estimated by using semi-empirical (AM1; PM3) and $a b$ initio (B3LYP//6-31G(d); HF// 6-31G(d)) methods are also described (Table 1). The morphology of all the solid samples obtained with nor-harmane and other matrices was studied and selected images obtained with the former are included in the present paper (Figure 7). 
The examples studied show that nor-harmane works as an efficient matrix. The goal of this study is to provide a quite useful matrix for polymers analysis and several polymer-nor-harmane combinations of use as UV-MALDI standards for $\mathrm{m} / \mathrm{z}$ calibration in positive and negative ion modes (Figures 1-6).

\section{Results and Discussion}

\section{PEG analysis}

Firstly, in order to compare the potential use of nor-harmane and GA as UV-MALDI matrix for synthetic commercial polymers belonging to the family of polar water-soluble polymers, several experiments were conducted. Thus PEG 3350, PEG 5000 and PEG 8000 were selected as analytes and dissolved in $\mathrm{NaCl}(0.5 \mathrm{mg} / \mathrm{mL})$ water-ethanol 9:1 (v/v) solution. The positive ion mass spectra obtained from polyethyleneglycol 8 kDa (PEG 8000) with nor-harmane and GA as matrix are illustrated in Figures $1 \mathrm{a}$ and $1 \mathrm{~b}$ respectively.

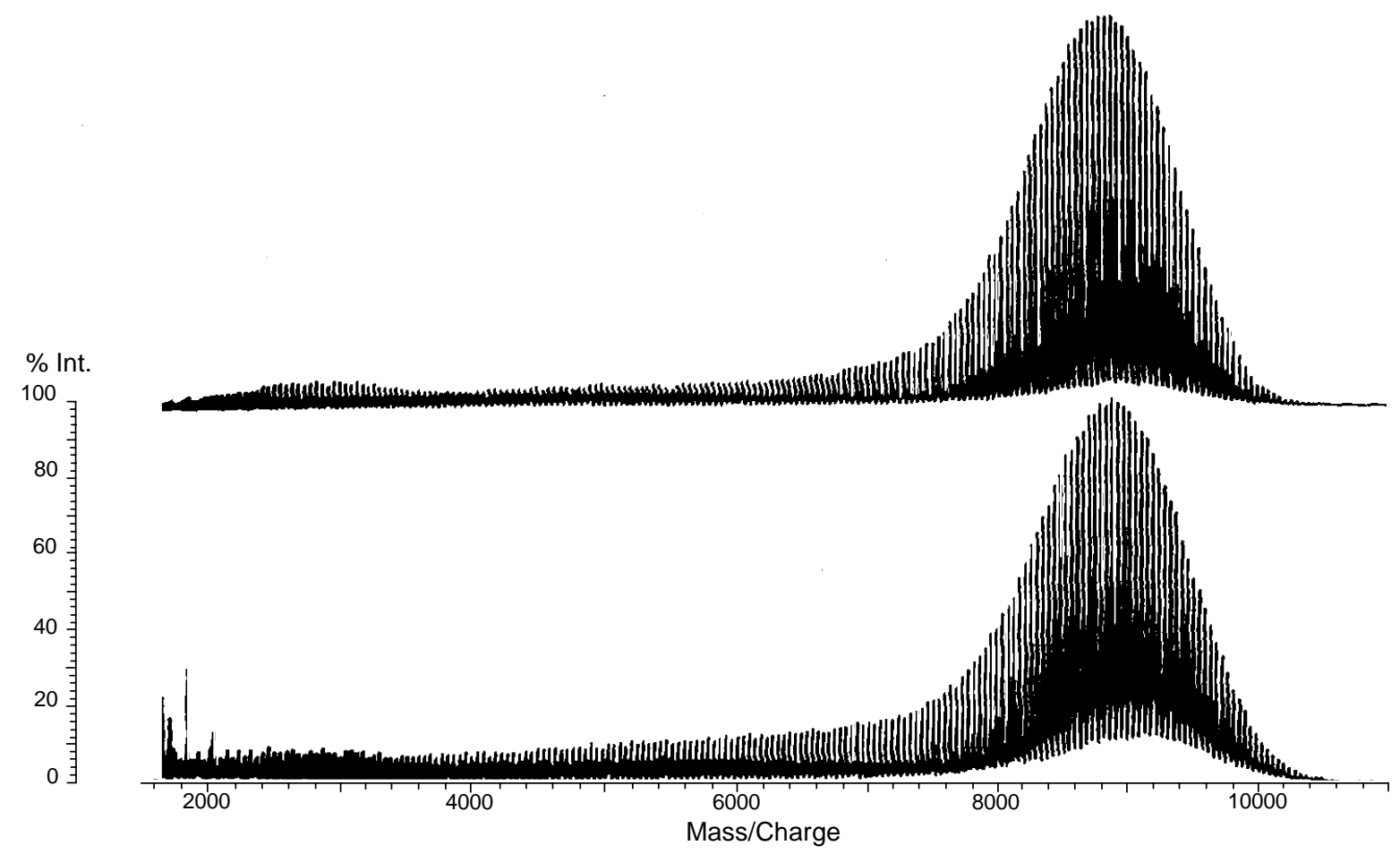

Figure 1. UV-MALDI-TOF mass spectra of PEG 8000 in linear positive ion mode; (a) matrix: nor-harmane; (b), matrix: GA.

Figure 1a shows well resolved adjacent oligomer signals with high intensity for masses ranging from 7000 to $10000 \mathrm{Da}$, reflecting the molecular weight distribution of PEG 8000. As can be seen, the quality of this spectrum is higher than that obtained with GA shown in Figure 1b, with 
lower resolution of the PEG 8000 signals and higher intensity of the matrix clusters signals ( $\mathrm{m} / \mathrm{z}$ range: 1500-6000 Da). In negative ion mode the results obtained shown a more dramatic difference between nor-harmane and GA performance as UV-MALDI matrices. While norharmane yielded a quite intense and differentiated patter of oligomer signals GA did not produce any signal in the $7000-10000 \mathrm{~m} / \mathrm{z}$ range (Figures $2 \mathrm{a}$ and $2 \mathrm{~b}$ ).

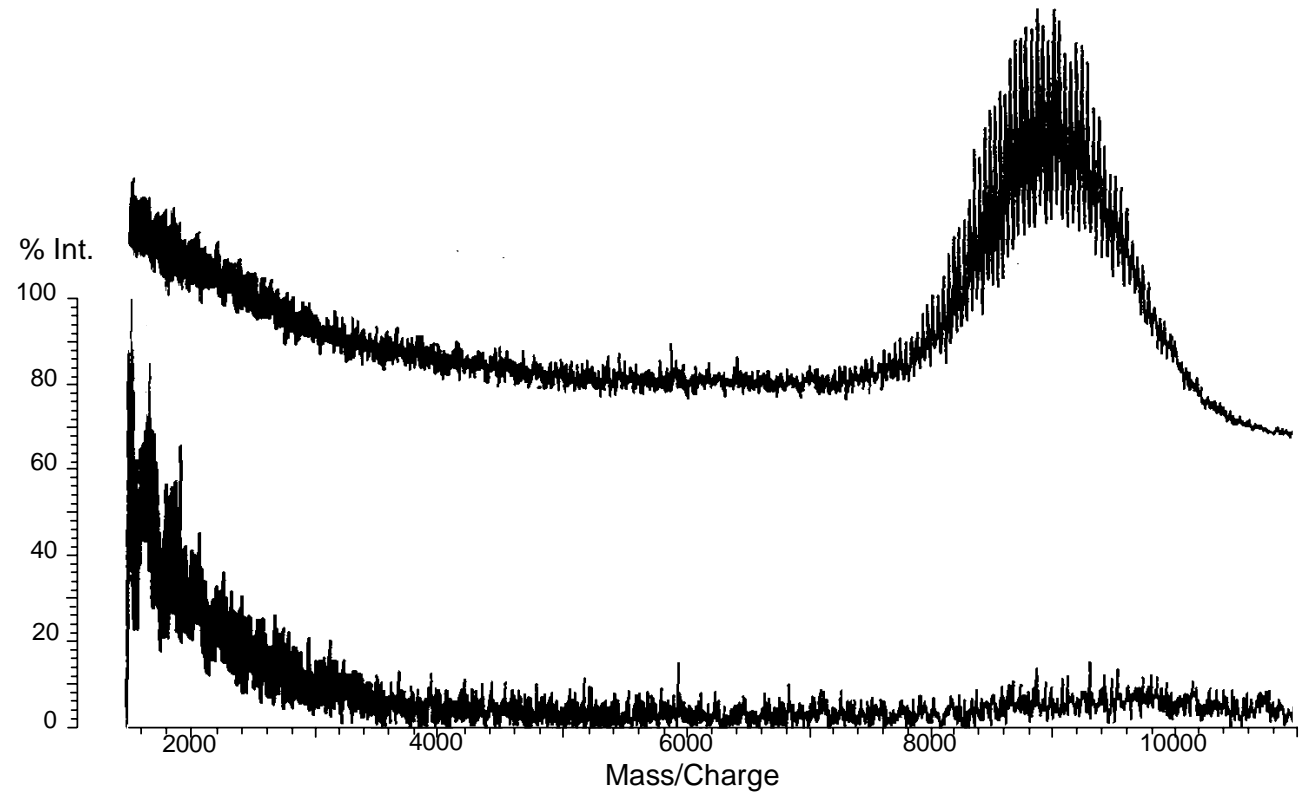

(a)

Figure 2. UV-MALDI-TOF mass spectra of PEG 8000 in linear negative ion mode; (a) matrix: nor-harmane; (b), matrix: GA.

\section{PS analysis}

The capability of this technique to determine accurate molecular weight values for hydrophobic (non-polar) polymers was first shown for polystyrene (PS) with molecular weights up to $8 \mathrm{kDa}$ using as matrix a liquid mixture of 2-nitrophenyl octyl ether (NPOE) and silver trifluoroacetate (AgTFA) for cationization. ${ }^{5,34}$ Afterwards, the use of organic solvents for the UV-MALDI-MS analysis of organic-soluble polymers was generally accepted. Thus, the use of matrices soluble in organic solvents allowed direct mixing with organic soluble polymers promoting better polymermatrix interaction and yielding better results. ${ }^{5,6,34,35}$ The potential of using nor-harmane for the analysis of synthetic non-polar polymers such as polystyrenes is demonstrated in Figures 3 and 4. Polystyrene 4700 Da (PS 4700) is used as analyte and tetrahydrofuran (THF) was used as solvents for both the matrix and the polymer. Figure 3 shows the spectrum obtained in positive linear mode, without any metal added as a cationizing agent, following for sample preparation the method A described in the Experimental Section. Furthermore, when the UV-MALDI-MS experiments were conducted in negative ion mode a quite clear spectrum was obtained for the same polymer. When $\mathrm{Ag}^{+}$was added as cationizing agent (methods B and C, Experimental) 
although the oligomers signals were shifted at $\mathrm{m} / \mathrm{z}=\mathrm{M}+108$, any significant modification of the spectrum quality was observed. In Figure 4 is shown the spectrum obtained in negative linear mode, without any metal added as ionizing agent. Although spectra of lower signal to noise ratio and intensity were obtained in the negative ion mode (compare spectra of Figures 3 and 4) the fact that for each signal the $\mathrm{m} / \mathrm{z}$ value can be assigned as $\mathrm{M}-\mathrm{H}$ is a quite useful tool for oligomers molecular weight and structure assignment.

As it was summarized by Belu et. al. ${ }^{35}$ PS have been previously analyzed with different matrix: $\mathrm{Ag}^{+}$:solvent combinations. The authors recommend the system dithranol: AgTFA: $\mathrm{CHCl}_{3}$ as the best for post source decomposition (PSD) or post source fragmentation analysis. In agreement with these authors we could not get reproducible signals when GA alone or the combination of GA and $\mathrm{Ag}^{+}$were used as matrix.

The current results shown in Figures 3 and 4 allow us to recommend the usage of norharmane in THF (or other organic solvent), without $\mathrm{Ag}^{+}$salts added, as a potential matrix in PS UV-MALDI-MS analysis.

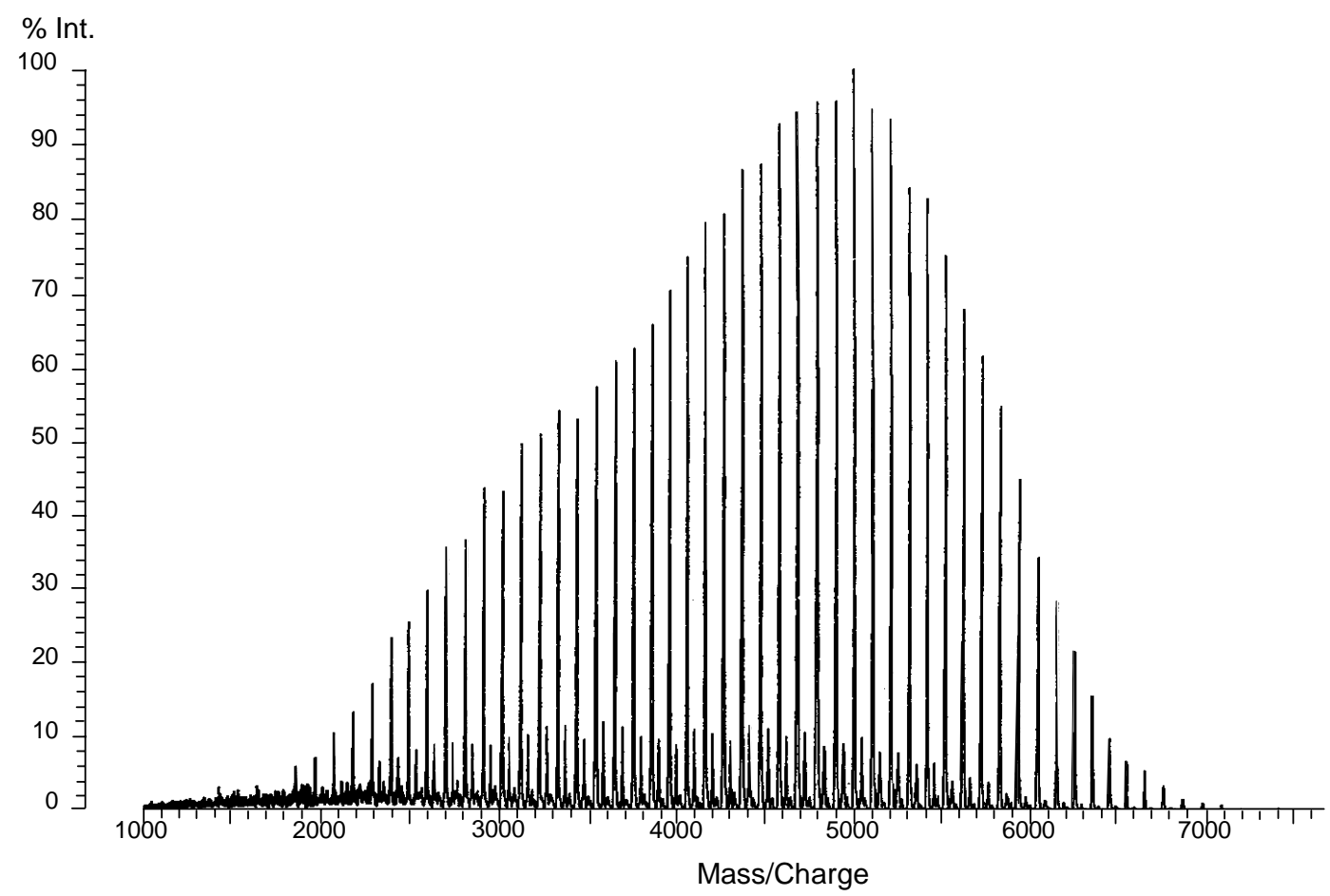

Figure 3. UV-MALDI-TOF mass spectrum of PS 4700 in linear positive ion mode; matrix: norharmane. 


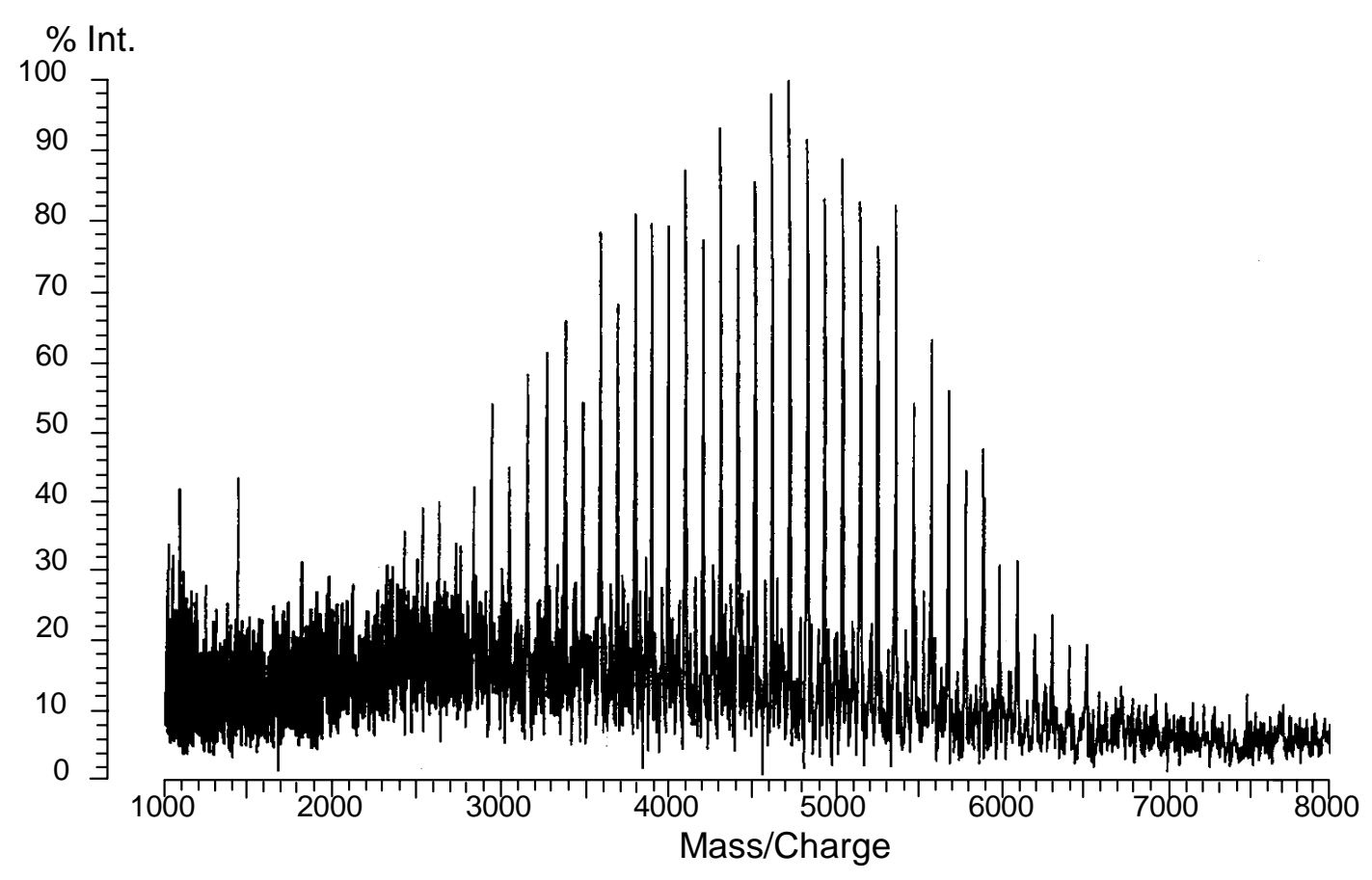

Figure 4. UV-MALDI-TOF mass spectrum of PS 4700 in linear negative ion mode; matrix: norharmane.

\section{PMMA analysis}

UV-MALDI analysis of polymethylmethacrylates has been conducted by using several compounds as matrices. Among them the most popular are indoleacrylic acid (IAA) and GA. As it is known IAA shows self-polymerization even in fresh solutions and finally might obscure the mass spectrum up to several thuosands Daltons. ${ }^{5}$ In the same way, GA shows very clearly a pattern of clusters signals that resembles an authentic mixture of oligomers in a polymer. In order to conduct experiments by using nor-harmane as UV-MALDI matrix we decided to use commercial PMMA 3500. As sample preparation method in polymers analysis is quite critical, ${ }^{35}$ the three methods described in Experimental (methods A, B, and C) were applied to PMMA in THF solution. The best results were obtained by using the mixture of PMMA and nor-harmane prepared following methods $\mathrm{A}$ and $\mathrm{C}$. As is shown in Figure 5 spectra of high quality are obtained in linear and reflectron positve ion mode. In negative ion mode spectra with low resolution were obtained in the $\mathrm{m} / \mathrm{z}$ region between $1000-8000$ only when nor-harmane was used as matrix while no signals were obtained in experiments conducted with GA and IAA. 


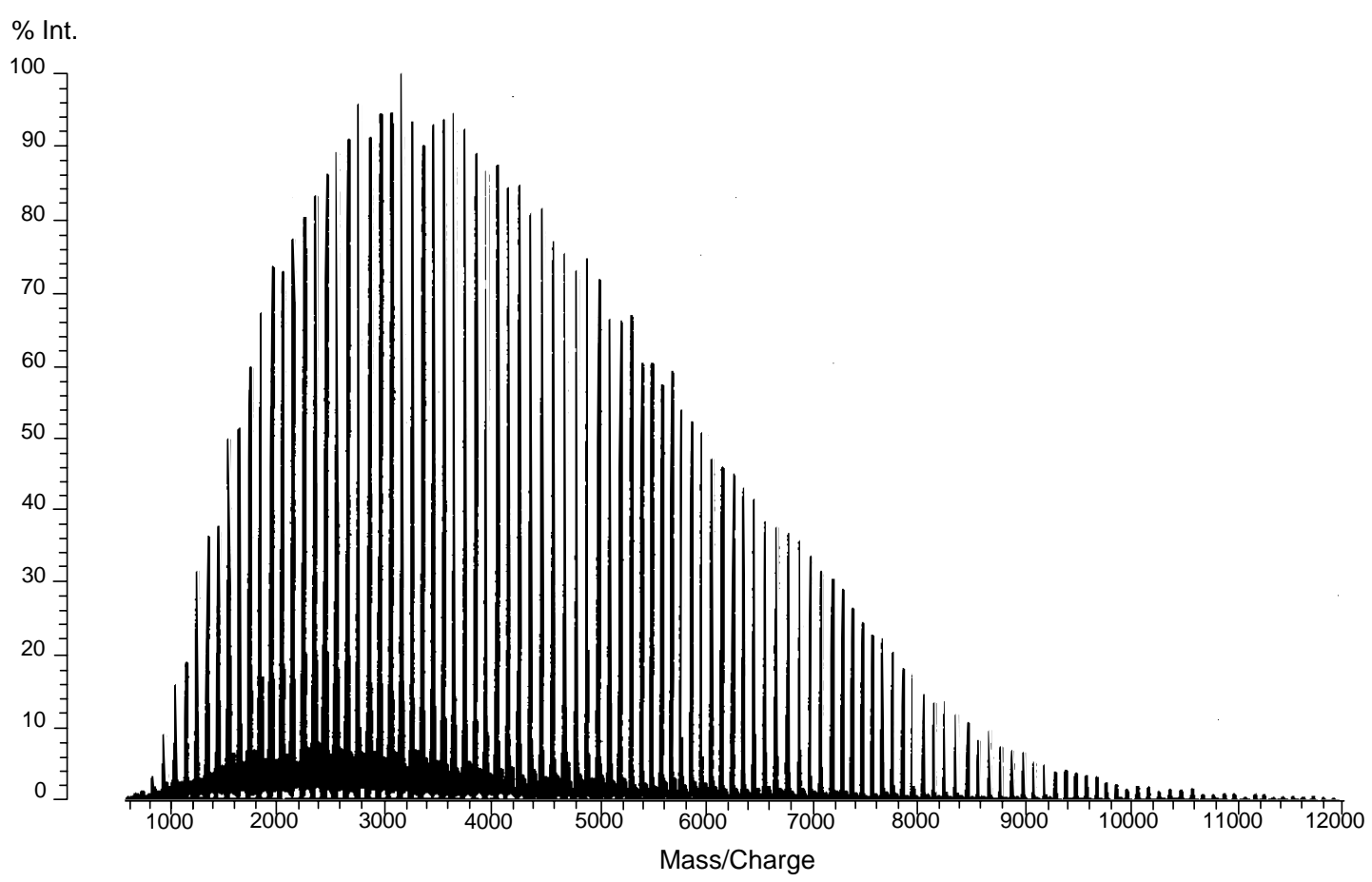

Figure 5. UV-MALDI-TOF mass spectrum of PMMA 3500 in linear positive ion mode; matrix: nor-harmane.

\section{PDMS analysis}

Polymers containing Si in their structure constitute a large family of synthetic compounds. Polysiloxanes have a repeat unit of the form $\left[\mathrm{R}_{2} \mathrm{SiO}\right]$ with silicon coordinated to two bridging oxygen atoms, while polysilsesquioxanes have silicon coordinated with three bridging oxygen atoms in the form of $\left[\mathrm{RSiO}_{3 / 2}\right]$. As a result, polysiloxanes are generally linear polymers, whereas polysilsesquioxanes can form a wide variety of complex three-dimensional structures. Recently we have described the UV-MALDI analysis of four families of new polysilsesquioxanes whose oligomers structure could be assigned. ${ }^{21-25}$ In these papers we only described in detail the spectra obtained in positive ion mode, and results of similar quality were obtained with various matrices i.e. GA, IAA, HABA and nor-harmane. Simultaneously, Wallace et. al. ${ }^{37}$ described the use of sinapinic acid (SA) and dithranol as matrices for another family of new polysilsesquioxanes. The structure of the organic subsituent $\mathrm{R}$, that distinguish one family of polysilsesquioxanes from another, explains why matrices with different polarity can work efficiently in UV-MALDI analysis in positive ion mode.

In the present paper we want to show the spectrum obtained in a positive ion mode, by using nor-harmane as matrix for the analysis of commerciallly available poly(dimethyl)siloxane 2.25 $\mathrm{kD}$ (PDMS 2250) where $\mathrm{R}=\mathrm{CH}_{3}$. The absence of free hydroxyl groups as substituents in this structure accounts for the non-polar character (hydrophobic) ${ }^{5}$ of this polymer and the difficulty 
to lead desorption/ionization process efficiently. The best results were obtained by using THF as solvent for both the PDMS polymer and nor-harmane, and following the sample preparation methods $\mathrm{A}$ and $\mathrm{C}$ described in experimental. The high efficiency of the desorption/ionzation process shown in Figure 6 was obtained without any cationizing salt species added.

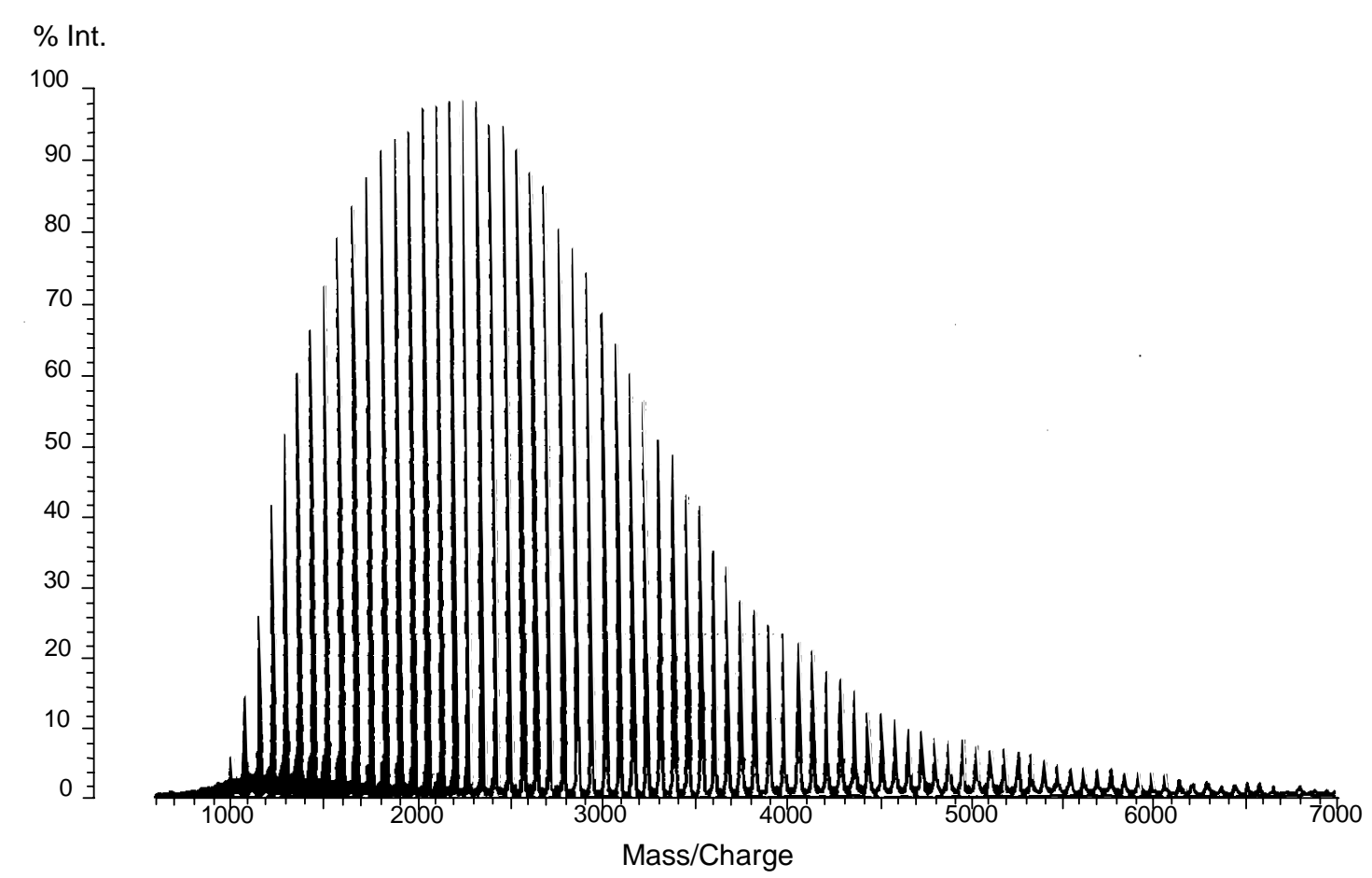

Figure 6. UV-MALDI-TOF mass spectrum of PDMS 2250 in linear positive ion mode; matrix: nor-harmane.

The morphology of the solid sample prepared with nor-harmane in $\mathrm{MeOH}-\mathrm{H}_{2} \mathrm{O}$ and in THF, after solvent evaporation can be seen in Figure 7 (top images). Furthermore, the morphology of the solids obtained after evaporation of the solvent for the mixtures PEG + nor-harmane, PS + nor-harmane, PMMA + nor-harmane and PDMS + nor-harmane are shown in the same figure.

As can be seen in all the cases crytallization of the matrix is still evident although lose the needle aspect in the PEG mixture (Figure 7, middle, left) and look as embedded in a transparent glass in the other three mixtures (Figure 7, middle, right and images in the bottom). 


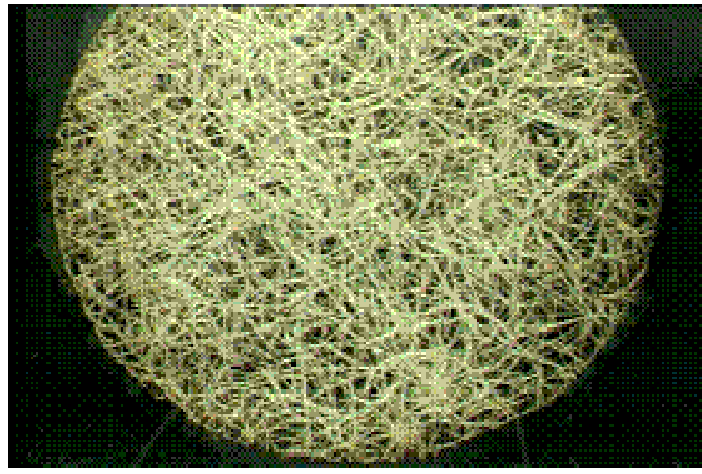

not-Harmane (from $\mathrm{MeOH}-\mathrm{H}_{2} \mathrm{O}$ )

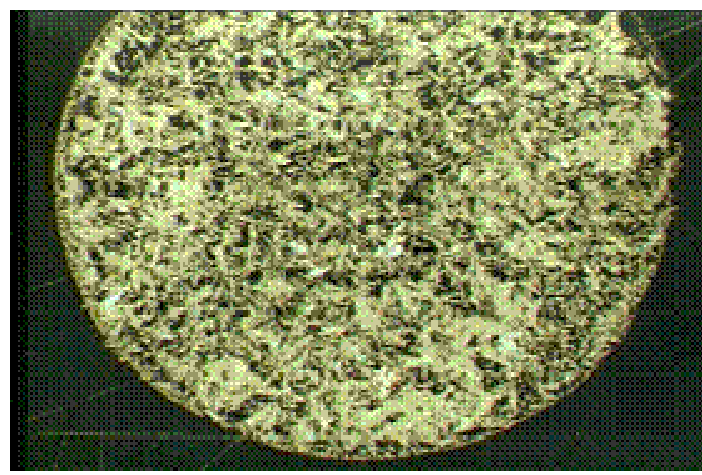

PEG + nor-hamane (from $\mathrm{MeOH}-\mathrm{H}_{2} \mathrm{O}$ )

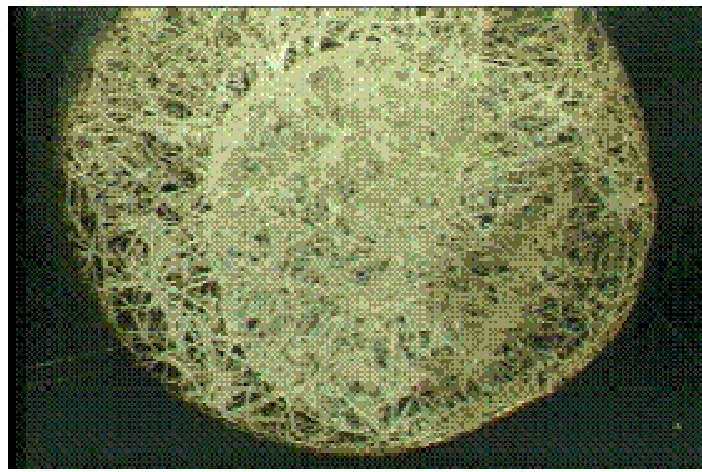

PMMA + nor-harmane (from $\mathrm{MeOH}-\mathrm{H}_{2} \mathrm{O}$ )

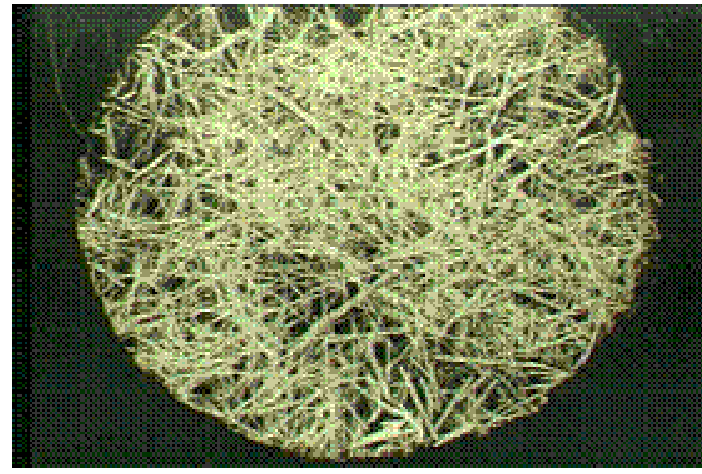

nor-Harmane (from THF)

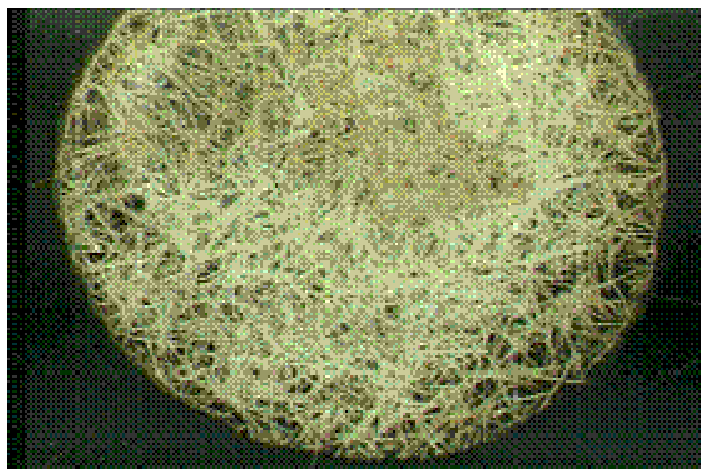

PS + nor-harmane (from THF)

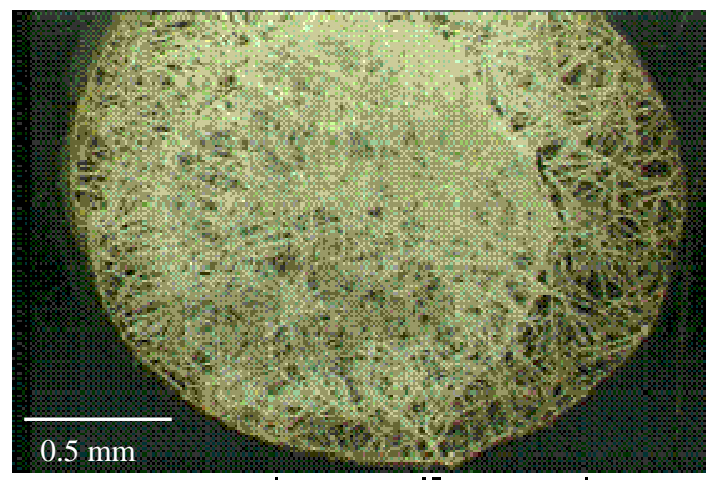

PDMS + nor-hamane (from THF)

Figure 7. Morphology of the solid samples prepared with PEG, PS, PMMA and PDMS by method C. Matrix: nor-harmane; the solvent used to prepare the mixture is indicated in parenthesis.

\section{$\mathrm{Ag}^{+}$salts as cationizing agent in UV-MALDI-MS}

Interestingly, in connection with the use of $\mathrm{Ag}^{+}$salts as cationizing agent in synthetic polymers analysis (PS, PMMA, PDMS among others), it is important to point that UV-MALDI can also produce strong-metal-rich cluster signals if the salts of silver in THF, DMSO or other organic solution are used together with nor-harmane, GA or other matrices (IAA, HABA, dihranol), in 
the presence or not of the polymers. In our experiments, when $\mathrm{Ag}^{+}$salts were added to the polymer samples we got sometimes the UV-MALDI-TOF spectra of Ag-containing clusters. In these spectra the oligomers signals are at a distance of 108 units of $\mathrm{m} / \mathrm{z}$ as average (52/48 natural abundance ratio of ${ }^{107} \mathrm{Ag} /{ }^{109} \mathrm{Ag}$ ). These spectra were obtained by adding silver trifluoroacetate, AgTFA, in THF to nor-harmane in the presence of PS and then loading the mixture on the sample container according to method C (Experimental). Similar spectra were obtained without the polymer (sample: matrix + AgTFA). Similar results were obtained adding AgTFA (THF) to other matrices such as IAA or HABA. These clusters peaks show that MALDI can produces metal-rich clusters although in the condensed phase, it is virtually impossible for metal salts to form pure metal or metal-rich clusters because the strong repulsion intreractions between metal ions of positive charges. Hence, it would be reasonable to expect that the metal-rich clusters cations observed were not formed in the condensed phase, but rather formed through gas-phase clustering reactions. Rashidezadeh and Guo have reported an investigation of metal attachment to polystyrenes in MALDI. ${ }^{38}$ THF was used as solvent for metal salts, PS and the matrix (dithranol). They describe for AgTFA peaks corresponding to clusters $\mathrm{Ag}_{\mathrm{n}}{ }^{+}$for $\mathrm{n}=1$ to $\mathrm{n}=9$ which do not show a gaussian distribution and depends on AgTFA /polyestyrene concentration ratio. The authors also point that some times they observed another Ag-containing cluster series in the range 500-1000 Da but they did not know about the nature of this cluster series.

In a recent paper Walker et al. ${ }^{39}$ describes, in the gase phase, stable coordination complexes of $\mathrm{Ag}(\mathrm{II})$ with different solvents (L; pyridine, acetonitrile, acetone, 2-butanone, tetrahydrofuran, benzene). Clusters ions $\left[\mathrm{Ag}(\mathrm{L})_{n}\right]^{+2}$ (n values in between 2 and 5) with intensities following the natural abundance ratio of 52/48 $\left({ }^{107} \mathrm{Ag} /{ }^{109} \mathrm{Ag}\right)$ have been observed. In conclusion we feel that stable cluster ions with the structure $\left[\mathrm{Ag}_{\mathrm{m}}(\mathrm{THF})_{\mathrm{n}}\right]^{+}$would account for our results. Thus, our results presents experimental evidence supporting the hypothesis that ionization of polymers in UV-MALDI is a complicated process and that the mechanism of cationizing analytes (i.e., polymers) doped with $\mathrm{Ag}^{+}$salts may change if different conditions are used. Additionally not only conditions such as type of matrices, polymers and cationizing agents but also solvents used for MALDI must be taken into account, because solvent as a complex-ligand can be fixed by the metal in the solid sample. ${ }^{39}$

In conclusion, although addition of $\mathrm{Ag}^{+}$salts have been extensively used in order to improve the ionization of non-polar polymers such as PS, PMMA and PDMS ${ }^{35}$ the possibility of using nor-harmane as a matrix without adding $\mathrm{Ag}^{+}$salts is strongly recommended.

\section{Nor-harmane}

Nor-harmane or $\beta$-carboline (9H-pyrido[3,4-b]indole) belongs to the group of natural products called alkaloids. Nor-harmane is composed of a $\pi$-defficient indole ring and a $\pi$-excessive pyridine ring (Figure 9, N). Therefore two functional sites for a acid-base chemistry are present, and consequently, at least, two $\mathrm{pK}_{\mathrm{a}}$ values exist, in the ground state and in the first electronic excited singlet state. $\mathrm{BH}^{+} \rightleftharpoons \mathrm{B}+\mathrm{H}^{+}, \mathrm{K}_{\mathrm{a}}=[\mathrm{B}]\left[\mathrm{H}^{+}\right] /\left[\mathrm{BH}^{+}\right], \mathrm{pK}_{\mathrm{a}}=-\log \mathrm{K}_{\mathrm{a}}$, and $\mathrm{BH}^{+*} \rightleftharpoons \mathrm{B}^{*}+$ $\mathrm{H}^{+}, \mathrm{K}_{\mathrm{a}}^{*}=\left[\mathrm{B}^{*}\right]\left[\mathrm{H}^{+}\right] /\left[\mathrm{BH}^{+*}\right], \mathrm{pK}_{\mathrm{a}}^{*}=-\log \mathrm{K}_{\mathrm{a}}^{*}$ with $\mathrm{BH}^{+}$cationic form (C) and $\mathrm{B}$ neutral form (N). 

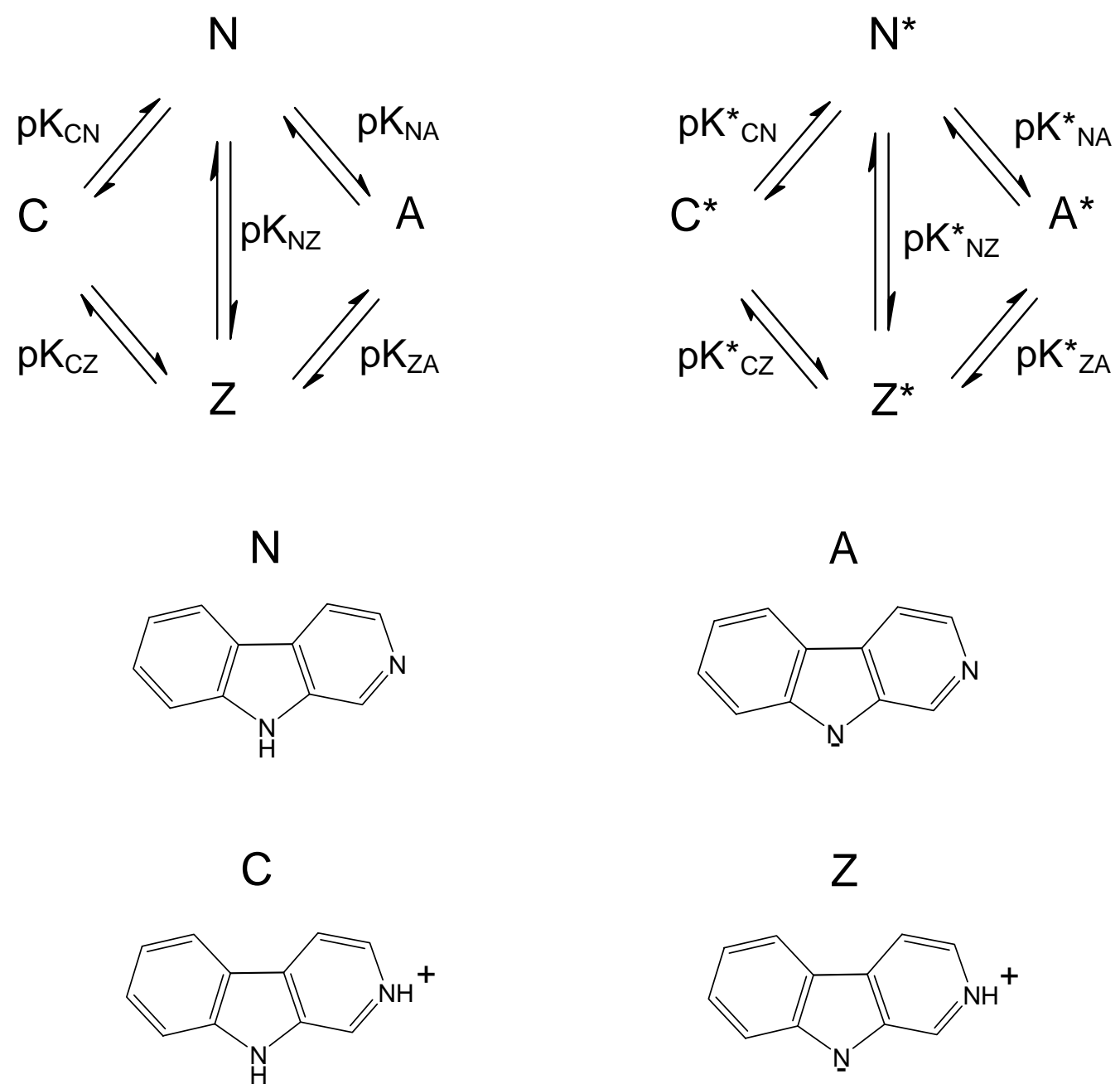

Figure 8. Acid-base equilibrium for nor-harmane in the ground and electronic excited state and structure of the species involved: N, neutral; A, anion; C, cation (protonated) and Z, zwitterion.

In addition the existence of an excited zwitterion has been shown. Hence the dependence of acid-base behaviour of this molecule on the acid-base properties of the environment which surrounds it is quite interesting. Though many papers have been published on that topic for norharmane in aqueous solutions (Draxler and Lippitsch ${ }^{40}$ and ref. there). As shown in Table 1 and Figure 8 for the equilibrium $\mathrm{C}-\mathrm{N}$ the $\mathrm{pK}_{\mathrm{a}}$ value increase drastically on going from the ground to the electronic excited singlet state (for $\mathrm{CN}$ equilibrium, $\mathrm{pK}_{\mathrm{a}}=7.9 ; \mathrm{pK}_{\mathrm{a}}{ }^{*}=14.7$ ). That means that nor-harmane behaves as a stronger basic compound in the latter state. Thus, it will be able to hold tightly those protons that are interacting through the hydrogen bridge with the pyridinic-N in the ground state. But, owing to its particular structure, on going from the ground to the electronic excited singlet state, if nor-harmane is located in a neutral or slightly basic environment the $\mathrm{N}-\mathrm{A}$ equilibrium changes also drastically (with $\mathrm{A}$, anionic form yielded after releasing the $\mathrm{H}$ from indolic $\mathrm{NH}$ group, ( Figure 8). As is shown in the same table, $\mathrm{pK}_{\mathrm{a}}$ and $\mathrm{pK}_{\mathrm{a}}{ }^{*}$ 
values for NA equilibrium are 14.5 and 8 respectively. In agreement with these results we informed similar changes in $\mathrm{pK}_{\mathrm{a}}$ values for nor-harmane $\mathrm{CN}$ equilibrium in acetonitrile ${ }^{41}$ (Table 1) and by using Förster cycle several $\Delta \mathrm{pK}_{\mathrm{a}}$ have been calculated in organic media and in water $\left(\Delta \mathrm{pK}_{\mathrm{a}}=\mathrm{pK}_{\mathrm{a}}^{*}-\mathrm{pK}_{\mathrm{a}} ; \Delta \mathrm{pK}_{\mathrm{a}}=7.1(\mathrm{MeOH}) ; 6.9(\mathrm{EtOH}) ; 7.2\right.$ (isoPrOH); 7.0 (terBuOH); 8.5 ( $\mathrm{MeCN}) ; 8.9\left(\mathrm{CH}_{2} \mathrm{Cl}_{2}\right)$; $5.5\left(\mathrm{H}_{2} 0\right){ }^{41,42}$ In additional photochemical experiments, we also show that in solid state nor-harmane forms quite tight hydrogen bridges through indole-NH and pyridine- $\mathrm{N}$ groups with other neighbours nor-harmane molecules ${ }^{43,44,45}$ because its UV absorption, excitation and fluorescence spectra resemble to those of the protonated species formed in acid solutions. ${ }^{43,44,45,46,47,48}$ Similar tight hydrogen bridges through indole-NH and pyridine- $\mathrm{N}$ groups between neighbouring nor-harmane molecules in solid state have been described by X Ray analysis. ${ }^{43}$

UV-LD and UV-MALDI-MS experiments are photochemical reactions in the solid state (nor-harmane $+\mathrm{h} v(337 \mathrm{~nm}) \rightarrow$ nor-harmane*). Thus, when UV-LD-MS experiments are conducted, after reaching the electronic excited singlet state the desorption/ionization of norharmane (m.w. 168 Da) yields protonated (C; m.w. 169 Da) and deprotonated (anionic, A; m.w. 167) species that are easily detected in positive and negative ion modes. When UV-MALDI experiments with nor-harmane as matrix are conducted, nor-harmane works as a photosensitizer, and from its electronic excited state induce the desorption/ionization process of the analyte which is surrounded by the matrix molecules. Simultaneously acid-base equilibrium occurs and depending on the analyte structure, protonated analyte molecules as cations and/or deprotonated analyte molecules as anions might be produced. Although the former process is not the only way to produce cations in UV-MALDI, the latter would be the cause why within the matrices described in the literature nor-harmane is one of the few that yields anions efficiently.

Besides, a high efficient matrix energy transfer to the analyte when nor-harmane is used as UVMALDI matrix, expressed as a higher efficient analyte fragmentation in PSD mode analysis ${ }^{17}$ and low fragmentation of nor-harmane itself (see bellow LD-TOF-MS section), would account for the excellent behaviour of nor-harmane as matrix when polymers with complex structures are analysed.

Additionally proton affinity (PA) of nor-harmane in the gas phase were estimated using PM3 Hamiltonians for calculation. Proton affinity (PA) of a compound $\mathrm{M}$ is defined as minus the enthalpy change of the reaction $\mathrm{M}+\mathrm{H}^{+} \rightarrow \mathrm{MH}^{+}$(gas state), $\mathrm{PA}=\Delta \mathrm{H}_{\mathrm{f}}^{\mathrm{o}}(\mathrm{M})+\Delta \mathrm{H}_{\mathrm{f}}^{\mathrm{o}}\left(\mathrm{H}^{+}\right)-$ $\Delta \mathrm{H}_{\mathrm{f}}^{\mathrm{o}}\left(\mathrm{MH}^{+}\right)$. Recently, these properties have been taken into account to characterize classic MALDI matrices. A PA value of $206.2 \mathrm{kcal} / \mathrm{mol}$ was obtained for nor-harmane. PA values within 200 and $210 \mathrm{kcal} / \mathrm{mol}$ have been obtained for pyridoindoles, pyridylindoles and pyridylpyridoindoles. ${ }^{33}$ For GA and SA, PA values of 181.2 and $191.8 \mathrm{kcal} / \mathrm{mol}$ have been calculated. Furthermore, the optimised geometry at B3LYP/6-31G(d) level and the electrostatic potential 3D isosurface calculated are displayed in Figure 9. The high negative charge density on the pyridine $\mathrm{N}$ and its high PA value would account for the special cappability of nor-harmane to fix a proton and to yield efficiently analyte anions. 
(a)

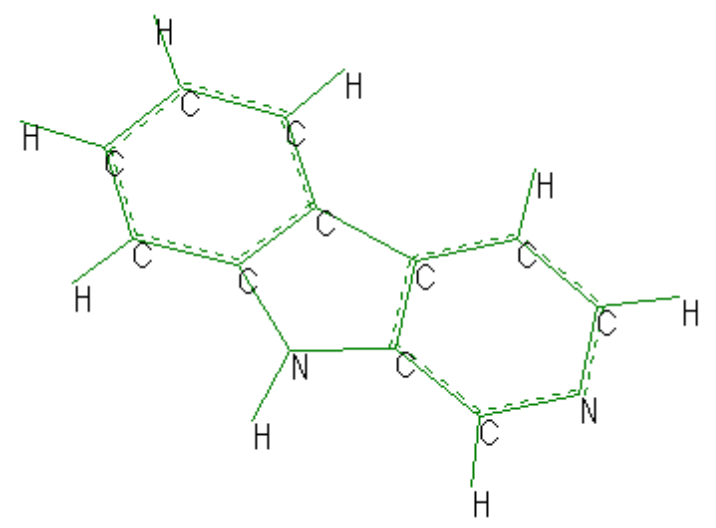

(b)

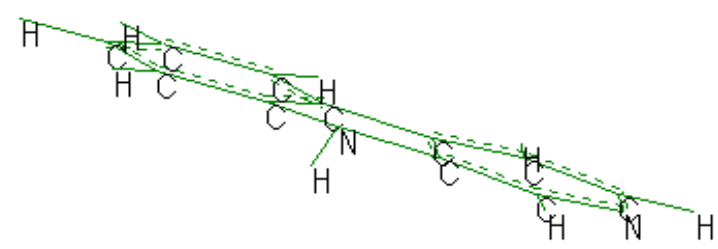

(c)

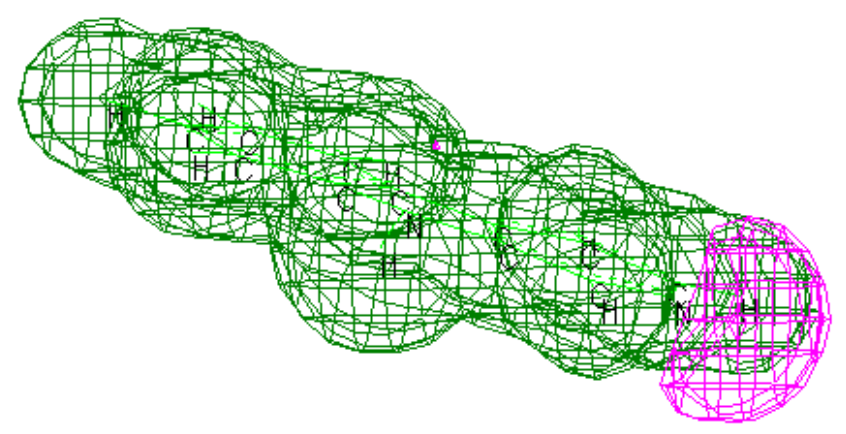

Figure 9. Optimized geometry ((a) and (b)) and electrostatic potential 3D isosurface (c) for norharmane calculated by computational chemistry. Details: (a) is rotated to (b); (b) and (c) are identical views of the molecule; (b) and (c) show that the molecule is flat.

UV-LD-TOF-MS obtained for nor-harmane is shown in Table 1 together with the corresponding EI-MS. For this compound the LD spectra obtained is quite simple. In the positive ion mode the protonated molecular ion is the most important signal and in some cases the corresponding protonated dimer structure is also observed. In the negative ion mode some minor fragments from the monomer and the dimmer structures are observed although the intact molecular ion is the predominant species detected in both ion modes. As conclusion, norharmane molecule is quite stable in UV-LD-TOF-MS experimental conditions and it does not release energy through fragmentation process. Thus, this energy can be efficiently used in desorption/ionization process during UV-LD and UV-MALDI. As is shown in the same table, this behaviour is quite different than that described for the EI-MS ${ }^{49}$ which shows the typical 
fragmentation of condensed polycyclic aromatic compounds $\left(\mathrm{M}^{+}-\mathrm{HCN} ; \mathrm{M}^{+}-(\mathrm{HCN})_{2} ; \quad \mathrm{M}^{+}\right.$HCN-C ${ }_{2} \mathrm{H}_{2}$ ) with few pendant substituents. ${ }^{50}$

Table 1. Several properties of nor-harmane checked as matrix in UV-MALDI-TOF-MS for synthetic polymer analysis in positive and negative ion modes

\begin{tabular}{|c|c|c|c|c|c|c|c|}
\hline Compound & $\begin{array}{l}\text { m.p. }{ }^{a} \\
\left({ }^{\circ} \mathrm{C}\right)\end{array}$ & $\begin{array}{l}\text { Absor } \\
\lambda 337 \\
\log \varepsilon \\
\left(\mathrm{mol}^{-1}\right.\end{array}$ & & $\begin{array}{l}\text { Absorp. } \\
\lambda_{\max }(\log \varepsilon) \\
(\mathrm{nm}) \\
\left(\mathrm{mol}^{-1} \mathrm{lcm}^{-1}\right)\end{array}$ & $\begin{array}{l}\text { Fluores. }^{b} \\
\lambda_{\max } \\
(\mathrm{nm}) ; \phi_{\mathrm{f}} \\
\left(\lambda_{\mathrm{exc}}=300\right. \\
\mathrm{nm})\end{array}$ & $\begin{array}{l}\mathrm{E}_{\text {ox }}^{0} \\
(\mathrm{~V} v s \\
\mathrm{SCE})^{\mathrm{c}} \\
(\mathrm{MeCN})\end{array}$ & $\begin{array}{l}\text { EI-MS }^{\mathrm{d}} \\
\mathrm{m} / \mathrm{z}(\%)\end{array}$ \\
\hline Nor-Harmane & $\begin{array}{l}198- \\
200\end{array}$ & 3.63 & & $\begin{array}{l}288(4.22) \\
338(3.63) \\
350(3.59)\end{array}$ & $368 ; 0.54$ & 1.44 & $\begin{array}{l}168\left(\mathrm{M}^{+}, 100\right) \\
140(28) \\
127(6), \\
114(8)\end{array}$ \\
\hline $\begin{array}{l}\text { Nor-Harmane } \\
\text { Hydrochloride }\end{array}$ & $\begin{array}{l}232- \\
235\end{array}$ & $3.14^{k}$ & & 374 (3.63) & 446 & & $\begin{array}{l}168\left(\mathrm{M}^{+}, 100\right), \\
140(28), \\
127(6), \\
114(8)\end{array}$ \\
\hline $\begin{array}{l}\text { LD-TOF- } \\
\mathrm{MS}^{\mathrm{e}} \\
\mathrm{m} / \mathrm{z}(\%) \\
(+) \text { ion mode }\end{array}$ & \multicolumn{2}{|c|}{$\begin{array}{l}\text { LD-TOF- } \\
\text { MS }^{\mathrm{e}} \\
\mathrm{m} / \mathrm{z}(\%) \\
\text { (-) ion mode }\end{array}$} & \multicolumn{2}{|c|}{$\begin{array}{l}\mathrm{pK}_{\mathrm{a}}^{\mathrm{g}} \\
\text { (ground } \\
\text { state) } \\
\text { (solvent) }\end{array}$} & $\begin{array}{l}\quad \mathrm{pK}^{*}{ }_{\mathrm{a}} \\
\text { lower singlet } \\
\text { excited state) } \\
\text { (solvent) }\end{array}$ & \multicolumn{2}{|c|}{$\begin{array}{c}\text { Decay time } / \mathrm{ns} \text { h,i,j } \\
\left(\lambda_{\text {exc }}=337 \mathrm{~nm}, \lambda_{\text {em }}=370\right. \\
\text { nm) } \\
\text { (solvent) }\end{array}$} \\
\hline $\begin{array}{l}335\left([\mathrm{D}+\mathrm{H}]^{+}\right. \\
\mathrm{f}, 36), \\
169\left([\mathrm{M}+\mathrm{H}]^{+},\right. \\
100)\end{array}$ & $\begin{array}{l}225(10 \\
167(10 \\
113(44\end{array}$ & & $\begin{array}{l}\text { (wa } \\
\mathrm{pK}_{\mathrm{c}} \\
\mathrm{pK}_{\mathrm{c}} \\
\mathrm{pK}_{\mathrm{N}} \\
\mathrm{pK}_{\mathrm{Z}} \\
(\mathrm{M}\end{array}$ & $\begin{array}{l}\text { ter })^{\mathrm{h}, \mathrm{i}} \\
7.9 \\
10.9 \\
14.5 \\
11.5 \\
\mathrm{CN})^{\mathrm{I}} \\
4.9\end{array}$ & $\begin{array}{c}\text { (water) }{ }^{\mathrm{h}, \mathrm{i}} \\
\mathrm{pK}^{*}{ }_{\mathrm{CN}} 12.2 \\
\mathrm{pK}^{*}{ }_{\mathrm{CZ}} 12 \\
\mathrm{pK}^{*}{ }_{\mathrm{NA}} 7.7 \\
\mathrm{pK}^{*}{ }_{\mathrm{ZA}} 13.9 \\
(\mathrm{MeCN})^{\mathrm{j}} \\
23.4\end{array}$ & $\begin{array}{r}22 \\
5.68 \\
4.1 \\
1.62 \\
1.6\end{array}$ & $\begin{array}{l}(\text { water }) \\
\left.\mathrm{pH}^{2}=3.6\right)^{\mathrm{i}} \\
(\mathrm{pH}=11.2)^{\mathrm{i}} \\
(\mathrm{pH}=11.4)^{\mathrm{i}} \\
(\mathrm{pH}=11.8)^{\mathrm{i}} \\
(\mathrm{pH}=14)^{\mathrm{i}}\end{array}$ \\
\hline
\end{tabular}

${ }^{\mathrm{a}}$ Data from: The Merck Index, $9^{\text {th }}$ Edition (1976). ${ }^{\mathrm{b}}$ Spectra obtained in EtOH (Atmosphere: air). ${ }^{c} E^{0}$ ox redox potential of nor-harmane measured vs SCE in acetonitrile. ${ }^{\mathrm{d}}$ From Ref. ${ }^{49}$ e UV-LD-TOF-MS for GA (m/z): 155, 138, 111. ${ }^{\mathrm{f}} \mathrm{D}=2(\mathrm{M}-\mathrm{H})$, photochemical dimer (Ref. $\left.{ }^{49}\right){ }^{\mathrm{g}}$ GA, $\mathrm{pK}_{\mathrm{a}}=2 . .93 .{ }^{\mathrm{h}}$ From Ref. ${ }^{40}$. ${ }^{\mathrm{i}}$ From Ref.. ${ }^{43 . \mathrm{j}}$ From Ref. ${ }^{41} \cdot{ }^{\mathrm{k}}$ Data obtained in EtOH-HCl. 
Additionally, as mentioned above, the amount of adduction is negligible in synthetic polymers analysis although in nor-harmane LD-TOF-MS some cluster signals of very low intensity can be detected. Depending on the experimental conditions, dimer clusters in the 300350 Da region and some clusters looking as a mixture of (nor-harmane) $)_{n}$ oligomers in the 10005000 Da region can be observed. As the number and intensity of the clusters shown in the $\mathrm{m} / \mathrm{z}$ region < 500 Da by nor-harmane LD-MS is minor than that of other matrices such as GA and $\mathrm{SA}$, it is more suitable for low molecular mass analysis, i.e. for carbohydrate UV-MALDI analysis area in which still there is a shortage of useful matrices. ${ }^{9,11-14,16-18}$

\section{Conclusions}

In the present paper we show that nor-harmane is a quite useful matrix for the UV-MALDI-MS analysis of synthetic polymers with quite different chemical structure and as consequence with quite different polar properties. Thus, on going from hydrophilic (PEG) to hydrophobic (PS and PDMS) and passing through intermediate polar-polymers (PMMA) nor-harmane, without any ionizing salt added, works as a good matrix not only in positive ion mode but in negative ion mode too. This special property is quite important because when $\mathrm{Ag}^{+}$salts are used, the cluster signals with structure $\left.\left[\mathrm{Ag}_{\mathrm{m}} \text { (solvent }\right)_{\mathrm{n}}\right]^{+}$that can be formed will complicate the identification of the analyte signals. As in quite extensive reviews several matrices are recommended for synthetic polymer analysis, ${ }^{5,6}$ with the present paper we would like to add at these previous lists nor-harmane as a potential matrix to take into account for synthetic polymers UV-MALDI MS analysis.

\section{Experimental Section}

Materials. Matrices: $\beta$-Carboline 9H-pyrido[3,4-b]indole (nor-harmane) was purchased from Sigma. 2,5-Dihydroxybenzoic acid (DHB, gentisic acid, GA), sinapinic acid (SA), trans-3indolacrylic acid (IAA), 2-(4-hydroxyphenylazo)-benzoic acid (HABA) and dithranol, were obtained from Aldrich.

Analytes for calibration: Proteins, aprotinin (A1153, m.w. 6512), bovine insulin (I5500, m.w. 5733.5), angiotensin 1 (m.w. 1296.49) and angiotensin 2 (m.w. 1046.21) were obtained from Sigma. Carbohydrates, Neutral cyclic oligosaccharides: $\alpha$-cyclodextrin (cyclohexaamylose, m.w. 972.9), $\beta$-cyclodextrin (cycloheptaamylose, m.w. 1135), $\gamma$-cyclodextrin (cyclooctaamylose, m.w. 1297), heptakis(2,3,6-tri-o-methyl)- $\beta$-cyclodextrin (m.w. 1450), methyl- $\beta$-cyclodextrin (m.w. 1500) and 2-hydroxypropyl- $\beta$-cyclodextrin (m.w. 1722).

Commercial polymers: polyethylene glycols (PEG 3350, av. m.w. 3350; PEG 8000, av. m.w. 8000); polystyrene (PS 4700, av. m.w. 4700), polymethylmetaacrylate (PMMA 3500, av. m.w. 3500), poly(dimethyl)siloxane (PDMS 2250, av. m.w. 2250) were purchased from Aldrich. 
Inorganic salts: Copper acetate $\left(\mathrm{Cu}(\mathrm{ac})_{2}\right)$, Copper acetylacetonate $\left(\mathrm{Cu}(\mathrm{acac})_{2}\right)$, Silver nitrate $\left(\mathrm{AgNO}_{2}\right)$, Silver trifluoroacetate (AgTFA), and Silver acetylacetonate (Ag(acac)) were purchased from Aldrich. These metal salt were chosen because of its solubility in $\mathrm{H}_{2} \mathrm{O}, \mathrm{MeCN}$, $\mathrm{MeOH}, \mathrm{EtOH}$, THF and in DMSO.

Solvents: THF, MeCN, DMSO, MeOH and EtOH (Sigma-Aldrich HPLC grade), trifluoroacetic acid (TFA, Merck) were used as purchased without further purification. Water of very low conductivity (Milli Q grade; 56 - 59 nS/cm with PURIC-S, ORUGANO Co., Ltd., Tokyo, Japan) was used.

\section{Ultraviolet matrix-assisted laser desorption/ionization time-of-flight mass spectrometry.}

Instruments. Matrix-assisted ultraviolet laser desorption/ionization time-of-flight mass spectrometry was performed using three different devices: i) Shimadzu Kratos, Kompact MALDI III, ii) Shimadzu Kratos, Kompact MALDI 4 with pulse delay extraction (PDE), and iii) Applied Biosystems Voyager DE-STR. All the devices were equipped with a pulsed nitrogen laser ( $\lambda=337 \mathrm{~nm}$; pulse width $=3 \mathrm{~ns}$ ), and devices ii) and iii) with tunable PDE and PSD (MS/MS device) modes.

Experiments were performed using at first the full range setting for laser firing position in order to select the optimal position for data collection, and secondly fixing the laser firing position in the sample sweet spots. The samples were irradiated just above the threshold laser power for obtaining molecular ions and with higher laser power for studying cluster formation. Thus, the irradiation used for producing a mass spectrum was analyte dependent. Usually 100 spectra were accumulated. All samples were measured in the linear and the reflectron modes, in both the positive and the negative ion modes.

Sample preparation methods. Matrix solutions were made by dissolving $5 \mathrm{mg}$ of the selected compound in $0.5 \mathrm{~mL}$ of acetonitrile : water-trifluoroacetic acid $(0.1 \%) 2: 3(\mathrm{v} / \mathrm{v})$ for protein analysis, in $0.5 \mathrm{~mL}$ of acetonitrile : water $2: 3(\mathrm{v} / \mathrm{v})$ or $0.5 \mathrm{~mL}$ of methanol : water 2:3 (v/v) or 0.5 $\mathrm{mL}$ of water for carbohydrate and PEG analysis, and in $0.5 \mathrm{~mL}$ of THF : water 2:3 (v/v) or 0.5 $\mathrm{mL}$ of THF for synthetic non-water soluble polymer analysis. Analyte solutions of $10 \mathrm{pmol} / \mu \mathrm{L}$ were freshly prepared by dissolving the proteins in aqueous trifluoroacetic acid $(0.1 \%)$ and the carbohydrates in pure water. Polymers solutions $(1 \mathrm{mg} / \mathrm{mL})$ were prepared by dissolving PEGs in $\mathrm{NaCl}(0.5 \mathrm{mg} / \mathrm{mL})$ water-EtOH 9:1 (v/v) solution and polyesters, polyamides, polystyrenes and polysilanes in THF.

To prepare the analyte-matrix deposit three methods were used. In the first method (Method A), prior to the sample preparation $1.0 \mu \mathrm{L}$ of the matrix solution was placed on each sampleprobe plate in order to wash it, and then sucked dry with the same pipette tip. In order to make the analyte-matrix deposit, in general, $0.5 \mu \mathrm{L}$ of the analyte solution were placed on the sample probe plate ( $2 \mathrm{~mm} \times 1.5 \mathrm{~mm}$ square) and $1.0 \mu \mathrm{L}$ of the matrix solution was placed on the same probe plate using the same pipette tip that was used for washing and covering the analyte solution; then the solvent was removed by blowing air in the dark; the drying-time depends on the b.p. of the solvent used. Typically, $1.5 \mu \mathrm{L}$ as total volume of both solutions was used. 
In the second procedure (Method B; dried-droplet method or sandwich method ${ }^{12-14,33}$ ), $0.5 \mu \mathrm{L}$ of the matrix solution were placed on the sample probe tip and the solvent removed by blowing air in the dark, at room-temperature. Subsequently, $0.5 \mu \mathrm{L}$ of the analyte solution were placed on the same probe tip covering the matrix, and the solvent was removed again by blowing air. Then, two additional portions $(0.5 \mu \mathrm{L})$ of the matrix solution were deposited on the same sample probe tip. The matrix to analyte ratio used was 3:1 (v/v) and the matrix and analyte solution loading sequence was: i) matrix, ii) analyte, iii) matrix, iv) matrix.

Method C: the matrix and analyte solutions were prepared in the same solvent and mixed as follows: a $10 \mu \mathrm{L}$ volume of a polymer solution $(0.5 \mathrm{mg} / 0.5 \mathrm{~mL}$ in the proper solvent) was mixed with $50 \mu \mathrm{L}$ of matrix solution in order to obtain a molar ratio of matrix to polymer of about 1000:1. A $0.5 \mu \mathrm{L}$ volume of the final solution was deposited on the stainless-steel or gold plate, and dried in the dark, by using forced air during time solvent dependent.

Salt doping of polymer samples. Methods $\mathrm{B}$ and $\mathrm{C}$ were followed when $\mathrm{Na}^{+}, \mathrm{Cu}^{2+} \mathrm{and} \mathrm{Ag}^{+}$ were added as ionizing agent. $\mathrm{Cu}^{2+}$ and $\mathrm{Ag}^{+}$salt solutions were prepared and used under dark conditions and freshly prepared before each experiment. No stock $\mathrm{Cu}{ }^{2+}$ and $\mathrm{Ag}^{+}$salt solutions were used. When method B was used, $0.5 \mu \mathrm{L}$ of the solution of the salt $\left(4.5 \times 10^{-3} \mathrm{M}\right)$, in the proper solvent, was added to the sample; the sequence used to load the solutions on the sample probe tip was: i) matrix, ii) analyte, iii) salt solution iv) matrix, v) matrix. When method C was used, the solution that contains the polymer and the matrix was then mixed with the metal salt solution $4.5 \times 10^{-3} \mathrm{M}$ in the proper solvent, in a 5:1:1 ratio (v:v:v) matrix:polymer:metal salt prior the deposition of approximately $1.0 \mu \mathrm{L}$ on the sample stage.

The resulting crystalline layers were found to be relative homogeneous in the three cases depending on the analyte-matrix-solvent system studied. Thus the results shown and discussed in the present paper are the best obtained after checking the different samples preparation methods for each analyte-matrix pair studied.

Inspection of crystals from solids to be used as samples (stereoscopic microscope NIKON Optiphot, Tokyo, Japan; magnification x400 and high-resolution digital microscope Keyence VH-6300, Osaka, Japan; magnification x800) in UV-MALDI analysis showed that: a) GA shows preferential crystallization from the edge of the sample and large white crystals are observed; b) when GA is used as matrix a preferential crystallization from the edge of the sample is always observed; c) nor-harmane shows abundant and homogeneous crystallization all over the solid surface which dependes on te solvent used (Figure 7) and d) when of nor-harmane is used as matrix in PEG, PS, PMMA and PDMS analysis an abundant amount of crystals distributed all over the surface was observed (Figure 7).

Spectrum calibration. Spectra were calibrated by the use of external calibration reagents. In the lineal and reflectron modes, GA and SA as matrix were used in positive ion mode and norharmane in positive and negative ion modes. The Kratos Kompact and the Voyager DE-STR calibration programs were used.

Probe supports. Stainless steel probe supports (Shimadzu), were used in the Kratos, Kompact MALDI III and 4 devices. Welled gold sample plates were used in the Voyager DE-STR. 
Samples were placed at locations which were mirror-polished in order to get better images for morphological analysis.

UV/Visible and fluorescence spectroscopy. UV/visible absorption spectra were measured in ehanol solution at room temperature. Fluorescence emission and excitation spectra were measured in ethanol solution and adsorbed on solid supports at room temperature and in solid solutions at $77 \mathrm{~K}$.

Absorption spectra of the solutions were recorded with $1 \mathrm{~cm}$ stoppered quartz cells (Fine quartz cell, Japan) in a Shimadzu UV-3100 spectrophotometer, using the corresponding solvent as reference $(298 \mathrm{~K})$. The fluorescence measurements were performed on a Hitachi F-4500 fluorescence spectrophotometer whose output is automatically corrected for instrumental response by means of a Rhodamine B quantum counter with stoppered quartz cells, using the $90^{\circ}$ mode. The excitation spectra were measured on the same spectrometer.

Calculations. The ground-state optimized geometry of nor-harmane was calculated by using $a b$ initio calculations at B3LYP/6-31G(d) (Gaussian 98). ${ }^{51}$ Proton affinity (PA) of a compound M is defined as minus the enthalpy change of the reaction $\mathrm{M}+\mathrm{H}^{+} \rightarrow \mathrm{MH}^{+}$(gas state), $\mathrm{PA}=\Delta \mathrm{H}_{\mathrm{f}}^{\mathrm{o}}(\mathrm{M}$ ) $+\Delta \mathrm{H}_{\mathrm{f}}^{\mathrm{o}}\left(\mathrm{H}^{+}\right)-\Delta \mathrm{H}_{\mathrm{f}}^{\mathrm{o}}\left(\mathrm{MH}^{+}\right)$. Each $\Delta \mathrm{H}_{\mathrm{f}}^{\mathrm{o}}$ value has been calculated with PM3 Hamiltonians. The value of $\Delta \mathrm{H}_{\mathrm{f}}^{\mathrm{o}}\left(\mathrm{H}^{+}\right)=353.6 \mathrm{kcal} / \mathrm{mol}$ (PM3 Hamiltonians) has been taken from literature. ${ }^{33,52}$

\section{Acknowledgments}

We thank CONICET (PIP 904/98) (Argentina) and UBA (X027) (Argentina) and Heiwa Nakajima Foundation (Japan) for partial financial support. REB is research member of CONICET (Argentina). We thank Dr. K. Tanaka, Dr. Y. Fukuyama, Dr. M. C. Biondic, M. Nishioka and Y. Ishikawa for measurements. The present project was performed as part of the Academic Agreement between REB (FCEyN-UBA, Argentina) and HN (CA-EU, Japan) with the facilities of the High Resolution Liquid Chromatography-integrated Mass Spectrometry System of the United Graduated School of Agricultural Sciences (EU, Japan).

\section{References}

1. (a) Yoshida, T.; Tanaka, K.; Ido, Y.; Akita, S.; Yoshida, Y. Mass Spectroscopy 1988, 36, 59. (b) Tanaka, K.; Waki, H.; Ido, Y.; Akita, S.; Yoshida, Y.; Yoshida, T. Rapid Commun. Mass Spectrom. 1988, 2, 151.

2. Karas, M.; Hillenkamp, F. Anal. Chem. 1988, 60, 2299.

3. Beavis, R. C.; Chait, B.T. Rapid Commun. Mass Spectrom. 1989, 3, 432.

4. Schlag, E. W. Time-of-Flight Mass Spectrometry and Its Applications; Elsevier: New York, 1994, p 413.

5. Nielen, M. W. F. Mass Spectrom. Rev. 1999, 18, 309.

6. Montaudo, M. S. Mass Spectrom. Rev. 2002, 21, 108. 
7. Gross, M. L. Ed. Mass Spectrometry in Biological Sciences: A Tutorial; NATO ASI Series, Series C, Kluwer Acad. Pub.: London, 1990, Vol. 353, p 460.

8. Beavis, R. C.; Chait, B. T. Methods Enzymol. 1996, 270, 519.

9. (9) Harvey, D. Mass Spectrom. Rev. 1999, 18, 349. (b) Harvey, D. Proteomics 2001, 1, 311. (b) Harvey, D. Int. J. Mass Spectrom. 2002, 226, 1.

10. Strupat, K.; Karas, M.; Hillenkamp, F. 1991. Int. J. Mass Spectrom. Ion Processes. 1991, 111, 89.

11. Mohr, M. D.; Börnsen, K. O.; Widmer, H. M. Rapid Commun. Mass Spectrom. 1995, 9, 809.

12. Nonami, H.; Fukui, S.; Erra-Balsells, R. J. Mass Spectrom. 1997, 32, 287.

13. Nonami, H.; Tanaka, K.; Fukuyama, Y.; Erra-Balsells, R. Rapid Commun. Mass Spectrom. 1998, 12, 285.

14. Nonami, H.; Orcoyen, M.; Fukuyama, Y.; Biondic, M. C.; Erra-Balsells, R. An. Asoc. Quim. Argentina 1998, 85, 81.

15. Tanaka, K.; Nonami, H.; Fukuyama, Y.; Erra-Balsells, R. Proceedings of the 46 ${ }^{\text {th }}$ ASMS Conference on Mass Spectrometry and Allied Topics 1998, 1016.

16. Erra-Balsells, R., Kolender, A., Matulewicz, M. C., Nonami, H., Cerezo, A. S. Carb. Research. 2000, 329, 157.

17. Fukuyama, Y., Ciancia, M. C., Nonami, H., Erra-Balsells, R. Cerezo, A. S., Matulewicz, M. C. Carb. Research. 2002, 337, 1553.

18. Erra-Balsells, R.; Nonami, H. Environ. Control in Biolog. 2002, 40, 55

19. Iglesias, L. F.; Fukuyama, Y.; Nonami, H.; Erra-Balsells, R.; Baldessari, A. Biotech. Tech. 1999, 13, 923.

20. Orgueira, H. A.; Erra-Balsells, R.; Nonami, H.; Varela, O. Macromolecules 2000, 34, 687.

21. Eisenberg, P.; Erra-Balsells, R.; Lucas, J. C.; Mauri, A. N.; Nonami, H.; Riccardi, C. C.; Williams, R. J. J. Macromolecules 2000, 33, 1940.

22. Fasce, D. P.; Williams, R. J. J.; Erra-Balsells, R.; Ishikawa, Y.; Nonami, H. Macromolecules 2001, 34, 3534.

23. Williams, R. J. J.; Erra-Balsells, R.; Ishikawa, Y.; Nonami, H.; Mauri, A. N.; Riccardi, C. C. Macromol. Chem. Phys. 2001, 202, 2425.

24. Eisenberg, P.; Erra-Balsells, R.; Lucas, J. C.; Mauri, A. N.; Nonami, H.; Riccardi, C. C.; Williams, R. J. J. Macromolecules 2002, 35, 1160.

25. dell’ Erba, I. E.; Fasce, D. P.; Williams, R. J. J.; Erra-Balsells, R.; Fukuyama. Y; $\quad$ Nonami, H. J. Organomet. Chem. 2003, in press.

26. Hillenkamp, F.; Schurenberg, M.; Schulz, T.; Dreisewerd, K. Proceedings of the 45th ASMS Conference on Mass Spectrometry and Allied Topics; 1997, 1096.

27. Karas, M.; Bahr, U.; Stahl-Zeng, J. In Large Ions: Their Vaporization, Detection and Structural Analysis. Baer, T., By Ng, C.Y., Powis, I. Ed.; Wiley: New York, 1996, p 27-48.

28. Chen, X.; Beavis, R. C. Proceedings of the 45th ASMS Conference on Mass Spectrometry and Allied Topics; 1997, 1105.

29. Chen, X.; Carroll, J. A.; Beavis, R. C. J. Am. Soc. Mass Spectrom. 1998, 9, 885.

30. Karas, M.; Glückmann, M.; Schäfer, J. J. Mass Spectrom. 2000, 35, 1. 
31. Zenobi, R.; Knochenmuss, R. Mass Spectrom. Reviews 1998, 17, 337.

32. Feng, J.; Brown R S. Proceedings of the 45th ASMS Conference on Mass Spectrometry and Allied Topics; 1997, p 852.

33. Nonami, H.; Wu, F.; Thummel, R. P.; Fukuyama, Y.; Yamaoka, Y.; Erra-Balsells, R. Rapid Commun. Mass Spectrom. 2001, 15, 2354.

34. Danis, P. O.; Karr, D. E.; Mayer, F.; Holle, A.; Watson, C. H. Org. Mass Spectrom. 1992, 27, 843.

35. Belu, A. M.; DeSimone, J. M.; Linton, R. W.; Lange, G. W.; Friedman, R. M. J. Mass Spectrom. 1996, 7, 11.

36. Cook, K. J. Am. Soc. Mass Spectrom. 1998, 9, 267.

37. Wallace, W. E.; Guttman, C. M. Antonucci, J. M. J. Am. Soc. Mass Spectrom. 1999, 10, 224.

38. Rashidezadeh, H.; Guo, B., J. Am. Soc. Mass Spectrom. 1998, 9, 724.

39. Walker, N. R.; Wright, R. E.; Stace, A. J. J. Am. Chem. Soc. 1999, 121, 4837.

40. Draxler, S.; Lippitsch, M. E. J. Phys. Chem. 1993, 97, 11493.

41. Biondic, M. C.; Erra-Balsells, R. J. Chem. Soc., Perkin Trans. 2 1997, 1323.

42. Biondic, M. C.; Erra-Balsells, R. J. Chem. Res., (S). 1998, 114.

43. Biondic, M. C. Photochemistry of $\beta$-carbolines in diluted organic solution. Thesis, FCEyN, University of Buenos Aires, Buenos Aires, Argentina, 1996.

44. Biondic, M. C.; Erra-Balsells, R. J. Chem. Soc., Perkin Trans. 2 1992, 1049.

45. Biondic, M. C.; Erra-Balsells, R. J. Chem. Soc., Perkin Trans. 2 1993, 887.

46. Biondic, M. C.; Erra-Balsells, R. J. Photochem. Photobiol., Sec. A Chem. 1990, 51, 341.

47. Biondic, M. C.; Erra-Balsells, R. An. Asoc. Quim. Argentina 1993, 81, 403.

48. Biondic, M. C.; Erra-Balsells, R. J. Photochem. Photobiol. Sec. A Chem. 1994, 77, 149.

49. Erra-Balsells, R.; Frasca, A. R. Tetrahedron 1983, 39, 33.

50. Budzikiewicz, H.; Djerassi, C.; Williams, D. H. Mass Spectrometry of Organic Compounds. Holden-Day Inc, San Francisco, p72 and p566, 1967.

51. Frisch, M. J.; Trucks, G. W.; Schlegel, H. B.; Scuseria, G. E.; Robb, M. A.; Cheeseman, J. R.; Zakrzewski, V. G.; Montgomery, J. A.; Stratmann, R. E.; Burant, J. C.; Dapprich, S.; Millam, J. M.; Daniels, A. D.; Kudin, K. N.; Strain, M. C.; Farkas, O.; Tomasi, J.; Barone, V.; Cossi, M.; Cammi, R.; Mennucci, B.; Pomelli, C.; Adamo, C.; Clifford, S.; Ochterski, J.; Petersson, G. A.; Ayala, P. Y.; Cui, Q.; Morokuma, K.; Malick, D. K.; Rabuck, A. D.; Raghavachari, K.; Foresman, J. B.; Cioslowski, J.; Ortiz, J. V.; Stefanov, B. B.; Liu, G.; Liashenko, A.; Piskorz, P.; Komaromi, I.; Gomperts, R.; Martin, R. L.; Fox, D. J.; Keith, T.; Al-Laham, M. A.; Peng, C. Y.; Nanayakkara, A.; Gonzalez, C.; Challacombe, M.; Gill, P. M. W.; Johnson, B. G.; Chen, W.; Wong, M. W.; Andres, J. L.; Head-Gordon, M.; Replogle, E. S.; Pople, J. A. Gaussian, Inc., Pittsburgh, PA, 1998.

52. Trouk-Pointet, K.; A. Milliet, A.; Renou-Gonnord, M. F. J. Mass Spectrom. 1995, 30, 1495. 